\title{
Strategi Pemasaran Digital Produk Minuman Kopi di Masa Pandemi
}

\author{
Sandy Adithia ${ }^{1}$ dan Mega Puspita Perwira Jaya ${ }^{2}$ \\ 1,2 Institut Komunikasi dan Bisnis LSPR, Jakarta, Indonesia
}

\begin{abstract}
ABSTRAK
Indonesia merupakan salah satu negara produsen dan konsumen kopi terbesar di dunia. Hal ini terjadi karena bagi masyarakat Indonesia minum kopi merupakan salah satu tradisi untuk merayakan nilai kebersamaan dan mempererat tali persaudaraan. Peminum kopi di Indonesia kian meningkat dan keberadaan kedai kopi modern di Indonesia turut tumbuh bersamaan dengan tren tersebut. Namun pandemi Covid-19 dan kebijakan pemerintah dalam mengatasi penyebaran pandemi (penerapan PSBB) menjadi pukulan telak bagi industri kopi, khususnya industri kedai kopi. Namun kemunculan jenis kedai kopi baru yang memanfaatkan strategi pemasaran digital memiliki potensi sebagai jalan keluar dalam menjawab permasalahan yang ada. Bisnis yang dipilih sebagai fokus penelitian adalah Morfee Coffee, sebuah bisnis kedai kopi yang didirikan oleh mahasiswa IKB LSPR dan terkena imbas akibat pandemi Covid-19; Morfee Coffee terpaksa harus menutup kedainya dan sejak 2020 hingga kini merubah model bisnisnya berfokus pada pemasaran digital dalam menjawab tantangan di masa pandemi. Hal inilah yang menjadikan alasan Morfee Coffee dilirik sebagai fokus penelitian. Metode penelitian ini menggunakan pendekatan kualitatif dengan paradigma interpretatif dan menggunakan 7 bauran pemasaran serta SWOT. Hasil penelitian menunjukkan bahwa meskipun Morfee Coffee belum sepenuhnya melakukan pemasaran digital yang efektif, namun jika Morfee Coffee mengoptimalkan strategi pemasaran digitalnya, Morfee Coffee dapat memiliki model bisnis berkelanjutan di tengah pandemi.
\end{abstract}

Kata kunci: Kedai Kopi; Pandemi Covid-19; Pemasaran Digital; 7 Bauran Pemasaran; SWOT

\begin{abstract}
Indonesia is one of the largest coffee-producing and consuming countries in the world. This happens because for the people of Indonesia drinking coffee is a tradition to celebrate the value of togetherness and strengthen the brotherhood. Coffee drinkers in Indonesia are increasing and the existence of modern coffee shops in Indonesia is also growing along with this trend. However, the COVID-19 pandemic and government policies in overcoming the spread of the pandemic (implementation of $P S B B)$ have been a major blow to the coffee industry, especially the coffee shop industry. However, the emergence of new types of coffee shops that utilize digital marketing strategies has the potential as a way out in answering existing problems. The businesses chosen as the focus of the research are Morfee Coffee, a coffee shop business founded by IKB LSPR students and affected by the COVID-19 pandemic; Morfee Coffee was forced to close its shop and since 2020 until now has changed its business model to focus on digital marketing in responding to challenges during the pandemic. This is the reason Morfee Coffee is considered as the focus of research. This research method uses a qualitative approach with an interpretive paradigm and uses 7 marketing mixes and SWOT. The results show that although Morfee Coffee has not fully implemented effective digital marketing yet, if Morfee Coffee optimizes its digital marketing strategy, Morfee Coffee can have a sustainable business model during a pandemic.
\end{abstract}

Keywords: Coffee Shop; Covid-19; Digital Marketing; 7Ps Marketing Mix; SWOT 


\section{PENDAHULUAN}

Saat ini, Indonesia merupakan produsen dan juga konsumen kopi. Berdasarkan data International Coffee Organization (ICO) pada tahun 2020, sebagai produsen kopi, Indonesia berada di posisi ke 4 setelah Brazil, Vietnam, dan Colombia. Sedangkan sebagai konsumen kopi, konsumsi kopi Indonesia periode 2016/2017 mencapai 4,6 juta kemasan $60 \mathrm{~kg} / \mathrm{lb}$ (6o $\mathrm{kg}$ ) dan pada 2020, konsumsi kopi mencapai angka 5 juta. Data ini menunjukkan bahwa kopi merupakan minuman yang sangat digemari oleh masyarakat Indonesia. Bagi masyarakat Indonesia, minum kopi merupakan salah satu tradisi untuk merayakan nilai-nilai kebersamaan dan mempererat tali persaudaraan antar masyarakat. Maka, minum kopi yang berawal dari tradisi kemudian berkembang menjadi peluang bisnis dengan membuka kedai kopi. Keberadaan kedai kopi ini dapat menemani berbagai aktivitas sehari-hari mulai dari pekerjaan, hiburan, dan kebutuhan bersosialisasi bagi para pecinta kopi.

Dulu kedai kopi memiliki sarana yang minim dan kurang nyaman, namun kini kedai kopi identik dengan tempat yang nyaman karena dilengkapi dengan AC, WIFI, sofa atau tempat duduk yang nyaman serta desain interior yang unik. Inovasi juga dilakukan oleh para pemilik kedai kopi melalui kreasi menu dengan mengkombinasikan kopi dengan gula aren, minuman kopi dengan cita rasa buah, memberikan tambahan topping keju, susu almond dan bahkan ada yang mengkombinasikan dengan berbagai minuman khas daerah seperti kopi dengan kolak atau kopi dengan pisang hijau. Inovasi juga dilakukan pada cara penyajian produk minuman kopi seperti French press dan drip method atau kopi tetes. Rafiah (2020) menyampaikan bahwa kedai kopi Janji Jiwa melakukan inovasi dengan menghadirkan gaya baru dalam menikmati produk toast bread. Produk makanan pendamping kopi ini menjadi salah satu menu andalan kedai kopi Janji Jiwa dan menjadi nilai keunggulan bersaing dengan kedai kopi yang lain. Inovasi terus dilakukan untuk memberikan diferensiasi pada kedai kopi dibandingkan kompetitornya.

Bisnis kedai kopi di Indonesia memiliki potensi yang menjanjikan secara ekonomi. Hal ini terbukti dengan peningkatan jumlah kedai kopi yaitu pada tahun 2016, terdapat 1083 outlet dan meningkat menjadi 3000 outlet (Prasetyo, 2020). Namun sejak Pandemi Covid-19, bisnis kedai kopi mengalami penurunan. Pada awal Pembatasan Sosial Berskala Besar (PSBB) diluncurkan, kebijakan ini membatasi pelanggan untuk makan dan minum di kedai kopi dan hanya diperbolehkan layanan take away atau delivery order sehingga masyarakat memilih untuk mengonsumsi kopi di rumah. Pandemi Covid-19 juga mengubah perilaku konsumen yang lebih memilih mengonsumsi produk makanan dan minuman yang sehat. Ketua BPP HIPMI Bidang Industri, Perdagangan dan ESDM Rama Datau, menyatakan bahwa pada masa pandemi Covid-19 ini terdapat penurunan penjualan kedai kopi hingga 30\% (Hamdani, 2020). Oleh karena itu, diperlukan strategi pemasaran yang inovatif bagi kedai kopi agar mampu bertahan di tengah situasi pandemi ini.

Bauran pemasaran adalah seperangkat alat pemasaran yang digunakan perusahaan untuk terus menerus mencapai tujuan pemasarannya di pasar sasaran (Kotler \& Keller, 2016). Bauran pemasaran (marketing mix) terdiri dari: (1) Produk (Product) adalah segala sesuatu yang dapat ditawarkan kepada pasar untuk memuaskan suatu keinginan atau kebutuhan konsumen; (2) Harga (Price) adalah sejumlah uang yang mempunyai nilai tukar untuk memperoleh keuntungan dari memiliki atau menggunakan suatu produk; (3) Tempat/distribusi (Place) merupakan berbagai kegiatan yang dilakukan oleh perusahaan 
untuk membuat produknya mudah diperoleh dan tersedia pada konsumen sasaran. Distribusi memiliki peranan yang sangat penting dalam membantu perusahaan guna memastikan produknya. Hal ini dikarenakan tujuan dari distribusi adalah menyediakan barang dan jasa yang dibutuhkan dan diinginkan oleh konsumen pada waktu dan tempat yang tepat; (4) Promosi (Promotion) adalah semua kegiatan yang dilakukan perusahaan untuk mengomunikasikan dan mempromosikan produknya kepada pasar sasaran. Bauran promosi terdiri dari iklan, promosi penjualan (sales promotion), acara dan pengalaman (events and experiences), public relations and publicity, direct marketing, social media marketing, mobile marketing, word of mouth marketing dan penjualan personal; (5) Orang (People) adalah sumber daya manusia; (6) Proses (Processes) adalah cara penyampaian layanan kepada konsumen; dan (7) Bukti Fisik (Physical Evidence) adalah elemen fisik yang mendukung terciptanya layanan kepada konsumen.

Penelitian yang dilakukan oleh Gama (2018) pada implementasi khas dari kedai kopi lain. Kedai Tjangkir 13 mampu mengnyinergikan bauran pemasaran $7 \mathrm{P}$ mulai dari produk, harga yang ditawarkan, lokasi yang strategis, pelayanan yang cepat, interaksi komunikasi antara pemilik, karyawan dan konsumen melalui sapaan yang hangat kepada konsumen telah menjadi salah satu keunggulan Kedai Tjangkir 13. Komunikasi pemasaran berfokus pada social media marketing melalui penggunaan slogan seperti hangatnya kopi, hangatnya ceker pedas, hangatnya suasana, hangatnya pertemanan hanya di Tjangkir 13 Malang yang disampaikan dalam konten digital menarik dan menggambarkan dengan jelas tujuan dari layanan Kedai Tjangkir 13. Keller (2008) menyatakan bahwa slogan merupakan pesan persuasif yang singkat dan menarik bertujuan untuk menyampaikan informasi mengenai merek. Penggunaan slogan dapat menjadi salah satu taktik promosi yang tepat bagi kedai kopi.

Nasihin, et al. (2020), dalam penelitiannya mengenai strategi pemasaran Beby's Coffee dalam Era New Normal berdasarkan hasil analisis SWOT merekomendasikan bahwa strategi yang dapat dilakukan adalah: (1) tetap mempertahankan kualitas produk dan melakukan inovasi produk Kopi Seliter; (2) tetap mempertahankan harga produk yang terjangkau maupun promo-promo pada gofood dan grabfood; (3) memperluas lahan parkir; (4) tetap menjaga hubungan baik dengan karyawan agar karyawan merasa nyaman bekerja serta menjaga hubungan baik dengan para pemasok bahan baku produk kopi agar Beby's Coffee tetap mendapatkan bahan baku produk yang baik dengan harga yang relatif terjangkau; (5) tetap melaksanakan protokol kesehatan pencegahan COVID-19 agar customer tetap merasa nyaman dan aman saat menikmati kopi Beby's Coffee.

Digital marketing merupakan suatu aktivitas pemasaran agar produk atau jasa lebih dikenal oleh calon konsumen dan sekaligus mempengaruhi calon pembeli agar dapat membeli serta mengkonsumsi produk serta jasa perusahaan melalui media Internet (Oktaviani \& Rustandi, 2018). Hal ini menunjukkan bahwa digital marketing bukan hanya berfokus pada komunikasi pemasaran namun juga dapat menggambarkan saluran pemasaran. Saat ini digital marketing menjadi pilihan utama bagi pemasar karena memiliki beberapa keunggulan seperti jangkauannya yang luas, interaktif, informasi yang disampaikan terkini dan up-to-date, serta mudah dan bermanfaat dalam proses pembelian. Digital marketing juga menjadi pilihan bagi para wirausaha muda karena biaya yang murah namun memiliki dampak pemasaran yang signifikan. Temuan penelitian Hendrawan et al. (2019) menunjukkan bahwa digital marketing berpengaruh positif dan signifikan terhadap peningkatan kinerja penjualan 
UMKM. Digital marketing yang user friendly dan dapat menjangkau konsumen secara luas akan menjadi platform utama dalam pemasaran dan offline store akan menjadi pelengkap.

Kedai kopi merupakan salah satu usaha bisnis yang memanfaatkan keunggulan digital marketing melalui penerapan komunikasi pemasaran berbasis media sosial dalam mengomunikasikan produk minuman kopi. Kedai kopi KOZI memanfaatkan media sosial khususnya Instagram dalam memasarkan produk minuman kopi dan terbukti efektif dalam menyebarkan pesan promosi kepada pelanggan dengan cara yang cepat dan hemat biaya dibandingkan dengan media tradisional (Soedarsono et al., 2020). Teknologi digital juga membuat bisnis kedai kopi dapat merubah bentuk dari kedai kopi konvensional (menyediakan layanan dine-in) menjadi kedai kopi digital (hanya menyediakan layanan pemesanan secara online). Kedai kopi digital ini menarik untuk dikaji karena dapat menjadi strategi pemasaran yang inovatif agar mampu bertahan di pandemi Covid-19. Oleh karena itu, penelitian ini bertujuan untuk mengetahui dan menganalisis implementasi strategi pemasaran digital yang dilakukan oleh Morfee Coffee agar mampu bertahan dan bersaing di pandemi Covid-19.

\section{METODE PENELITIAN}

Penelitian ini menggunakan pendekatan kualitatif dengan paradigma interpretatif yang bertujuan mendapatkan wawasan terkait strategi pemasaran yang tepat guna mengembangkan Morfee Coffee di tengah pandemi Covid-19. Metode penelitian yang digunakan adalah deskriptif. Unit analisis dalam penelitian ini adalah individu yang merupakan pemilik dan karyawan Morfee Coffee. Peneliti akan melakukan wawancara pada para narasumber yaitu: (1) pemilik Morfee Coffee; (2) co-founder/barista/staf; dan (3) ahli pemasaran.

Metode pengumpulan data menggunakan wawancara mendalam yang dilakukan secara online. Analisis data dilakukan menggunakan teknik analisis data yang dikembangkan oleh Creswell (2014) yaitu: (a) menyusun dan menyiapkan data yang akan dianalisis; b) membaca keseluruhan data yang telah ditranskripsikan untuk mencari pemaknaan dari temuan penelitian; (c) melakukan coding pada data untuk mengkategorikan data; d) menggunakan hasil coding untuk mengelompokkan berdasarkan kategori; e) membuat laporan dari hasil coding dan kategori; dan (f) menginterpretasi data temuan penelitian kualitatif. Penelitian ini menggunakan analisis SWOT untuk mengidentifikasi berbagai faktor baik internal dan eksternal yang bertujuan untuk merumuskan strategi pemasaran perusahaan. Analisis ini didasarkan pada strategi pemasaran perusahaan agar dapat memaksimalkan kekuatan (Strengths) dan peluang (Opportunities), namun secara bersamaan dapat meminimalkan kelemahan (Weaknesses) dan ancaman (Threats). (Rangkuti 2014)

\section{HASIL DAN PEMBAHASAN}

\section{Gambaran Umum Morfee Coffee}

Terinspirasi dari masa kejayaan peradaban Roma yang memiliki banyak sekali filsuf, Morffee mempunya idealisme untuk menyemangati, mencerahkan, dan menemani kehidupan para pekerja yang ada di Indonesia. Di masa peradaban Roma yang begitu megah, banyak sekali pelajaran yang diberikan melalui para "pemikir" di zaman ini. Salah satu filsuf yang menjadi 
inspirasi Morfee adalah Marcus Aurelius dan Morfee Coffee melakukan apresiasi terhadap pribadi dan hasil karyanya sebagai semangat juang Morfee Coffee dalam memberikan makna bagi masyarakat Indonesia.

Morfee Coffee didirikan pada Januari tahun 2020 oleh Marfel Gideon, yang merupakan mahasiswa Institut Komunikasi dan Bisnis LSPR, bersama dengan Jeremy Zivanya selaku cofounder dan juga barista yang bersama meracik menu-menu kopi andalan Morfee Coffee. Akibat kondisi pandemi covid-19 yang terjadi di Indonesia sejak Maret 2020, Morfee Coffee yang sebelumnya memiliki kedai di Jakarta dan Bekasi, harus rela menutup kedai yang mereka sewa dan berfokus pada penjualan online. Morfee Coffee kini terletak di Jl. Permata Indah II Blok E no. 25, Perumahan Permata Bekasi 2, Kelurahan Duren Jaya, Kecamatan Bekasi Timur, Kota Bekasi. Meskipun Kedai Morfee Coffee kini sebagian besar difokuskan sebagai tempat produksi dan penjemputan saja, namun pemiliknya berharap kopi yang dijualnya tetap dapat dinikmati para pecinta kopi dengan harga yang terjangkau. Pasar sasaran yang dituju oleh Morfee Coffee adalah penikmat kopi berusia 18-28 tahun, dengan kelas sosial B dan C dan tinggal di kota Bekasi dan sekitarnya.

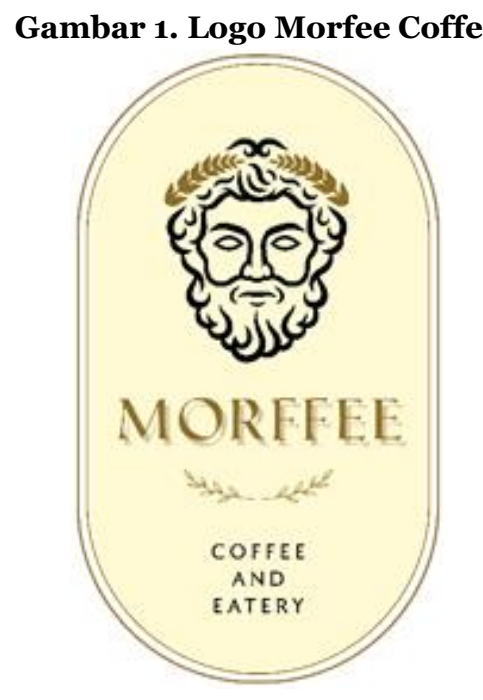

\section{Bauran Pemasaran Morfee Coffee}

Produk unggulan Morfee Coffee adalah Morfee Classic Coffee, Kopi susu Arabica yang diolah dengan metode cold brew untuk varian kopi dan Choco Commodus untuk varian non-kopi. Selain dua varian ini Morfee Coffee juga memiliki 2 varian menu lainnya yaitu Green Glacies dan Thai Glacies.

Kisaran harga produk minuman Morfee Coffee adalah Rp 18.00o - Rp 20.000. Meskipun Morfee Coffee menerapkan harga yang terjangkau menjadikan Morfee Coffee berada pada kisaran harga yang sesuai dengan target pasar yang dituju, namun Morfee Coffee memiliki kelemahan pada lokasi yang berada di tengah perumahan warga dan tidak berada di titik strategis. Meskipun begitu, Perumahan Permata Indah II masih dekat dengan beberapa titik strategis di Bekasi seperti Summarecon Bekasi dan Pekayon sehingga masih dapat dioptimalkan secara pendekatan online delivery. Morfee Coffee beroperasi dari hari Senin Jumat pukul 09.00 - 21.00 setiap harinya. Meskipun kedai yang dimiliki Morfee Coffee lebih berfokus pada pemesanan online, namun Morfee Coffee tetap melakukan protokol kesehatan seperti membersihkan dan melakukan desinfeksi tempat produksi setiap akan memulai dan 
selesai jam kerja, selalu mencuci dan membersihkan alat produksi setelah selesai dipakai, dan selalu mengenakan Alat Pelindung Diri saat bekerja. Morfe Coffee juga menerapkan sistem pembelian bahan baku yaitu berdasarkan stock checking. Setiap bahan baku tersisa sekitar 20\%, maka Morfee Coffee akan melakukan pembelian. Hal ini dilakukan agar pembelian bahan baku efektif dan tepat guna.

Taktik promosi yang digunakan oleh Morfee Coffee adalah sales promotion dengan memberikan gratis ongkir setiap pembelian 2 kopi dan memberikan diskon sebesar 10\% setiap pembelian diatas Rp 30.000 melalui GrabFood dan GoFood. Morfee Coffee menggunakan digital marketing dalam mengomunikasikan produknya melalui Facebook Ads (Instagram). Karena Morfee Coffee berfokus pada penjualan online maka taktik promosi digital menjadi penting, namun Morfee Coffee belum melakukan strategi pemasaran digital secara menyeluruh dan hal ini masih bisa ditingkatkan.

Karena kondisi pandemik, hingga kini Morfee Coffee masih dijalankan dengan efisiensi tinggi, yaitu oleh dua orang saja sebagai strategi untuk menerapkan efektivitas pengeluaran. Marfel Gideon bertanggung jawab dalam melakukan quality check, prokes, dan keuangan, serta Jeremy Zivanya yang bertanggung jawab sebagai kepala produksi (Barista) dan manajemen stock. Meskipun Morfee Coffee berfokus pada penjualan online (take away) namun juga Morfee Coffee tetap membuka layanan minum di tempat (dine in). Morfee Coffee dapat dibeli melalui aplikasi GrabFood dan GoFood.

Sebagaimana telah disebutkan sebelumnya, Kedai Morfee Coffee berlokasi di Perumahan Permata Indah II, Bekasi di mana Morfee Coffee memanfaatkan sebagian ruang rumah dan garasi sebagai kedai kopi. Karena ruang yang terbatas ini, Morfee Coffee lebih memfokuskan pada pembelian secara online alih-alih minum di tempat.

\section{Analisis SWOT (Strengths, Weaknesses, Opportunities dan Threats)}

Kekuatan (Strength) yang dimiliki oleh Morfee Coffee adalah: (1) produk kopi yang berkualitas; (2) harga yang terjangkau; (3) memiliki barista yang terlatih; (4) bermitra dengan GoFood dan GrabFood; dan (5) dekat lokasi strategis kota Bekasi. Kelemahan (Weaknesses) yang dimiliki adalah: (1) kondisi gerai yang dikhususkan untuk online membuat awareness sulit berkembang; (2) ruangan yang dimiliki tidak luas; (3) varian minuman yang terbatas; dan (4) belum ada varian menu yang benar-benar berbeda. Peluang (Opportunities) yang dapat dimanfaatkan oleh Morfee Coffee adalah potensi pasar yang masih terbuka. Sedangkan ancaman (Threats) yang dihadapi adalah: (1) penurunan omzet penjualan minuman kopi karena pandemi Covid-19; (2) persaingan yang ketat dengan kedai kopi lainnya; dan (3) Morfee Coffee belum relatif terkenal.

Tabel 1. Matrik SWOT Morfee Coffee

\begin{tabular}{|l|l|l|}
\hline Faktor Internal & Kekuatan (S) & Kelemahan (W) \\
\hline Faktor Eksternal & 1) Produk kopi yang & 1) Kondisi gerai yang \\
& berkualitas & dikhususkan online membuat \\
& 2) Harga yang terjangkau & awareness sulit berkembang \\
& 3) Memiliki Barista yang & 2) Varian minuman yang \\
& terlatih & terbatas \\
& 4) Bermitra dengan GoFood \& & 3) Belum ada varian menu yang \\
& GrabFood & benar-benar berbeda \\
\hline
\end{tabular}




\begin{tabular}{|c|c|c|}
\hline & $\begin{array}{l}\text { 5) Dekat lokasi strategis kota } \\
\text { Bekasi }\end{array}$ & \\
\hline $\begin{array}{l}\text { Peluang (O) } \\
\text { 1. Potensi pasar yang } \\
\text { masih terbuka }\end{array}$ & $\begin{array}{l}\text { Strategi SO } \\
\text { 1. Membuat racikan menu } \\
\text { dengan bahan yang berbeda, } \\
\text { berkualitas, namun terjangkau } \\
\text { 2. Membuat program } \\
\text { pemasaran yang membuat } \\
\text { Morfee Coffee lebih mudah } \\
\text { ditemukan calon pelanggan } \\
\text { 3. Membuat racikan menu } \\
\text { yang merespon kondisi } \\
\text { Pandemi }\end{array}$ & $\begin{array}{l}\text { Strategi WO } \\
\text { 1. Menambah berbagai taktik } \\
\text { promosi untuk pembelian take } \\
\text { away } \\
\text { 2. Memberikan diskon pada jam } \\
\text { operasi yang tidak ramai } \\
\text { 3. Mengoptimalkan kerjasama } \\
\text { dengan mitra yang sudah ada } \\
\text { untuk pembelian secara online. }\end{array}$ \\
\hline $\begin{array}{l}\text { Ancaman (T) } \\
\text { 1. Penurunan omzet } \\
\text { penjualan minuman } \\
\text { kopi karena pandemi } \\
\text { Covid-19 } \\
\text { 2. Persaingan yang } \\
\text { ketat di industri kedai } \\
\text { kopi lainnya } \\
\text { 3. Morfee Coffee } \\
\text { relatif belum terkenal }\end{array}$ & $\begin{array}{l}\text { Strategi ST } \\
\text { 1. Menambah variasi rasa khas } \\
\text { Morfee Coffee } \\
\text { 2. Membuat produk kopi } \\
\text { family package/paket bundle }\end{array}$ & $\begin{array}{l}\text { Strategi WT } \\
\text { 1. Meningkatkan promosi } \\
\text { berbasis digital dengan } \\
\text { memperbaiki konten dan } \\
\text { menggunakan KOL/infuencer } \\
\text { lokal (micro influencer) } \\
\text { 2. Membuat papan nama yang } \\
\text { besar dan menarik }\end{array}$ \\
\hline
\end{tabular}

Strategi bauran pemasaran yang bisa dilakukan oleh Morfee Coffee dalam menanggapi penerapan PSBB dan perubahan perilaku konsumen yang berubah-ubah selama pandemi antara lain adalah dengan membuat racikan menu yang merespon kondisi pandemi seperti meracik varian kopi jahe dan minuman sehat lainnya. Keberadaan barista sekaligus cofounder Morfee Coffee yang berpengalaman sebagai barista dan meracik menu minuman selama 3 tahun memungkinkan hal ini untuk diterapkan. Selain itu, Morfee Coffee juga perlu membuat racikan minuman baru yang dapat menjadi pembeda dengan para kompetitor lainnya. Melalui wawancara yang dilakukan kepada co-founder sekaligus pemilik kedai Morfee Coffee, mereka kini tengah menyiapkan satu varian kopi single origin yang berasal dari biji kopi pilihan Gunung Manglayang yang terkenal dalam kalangan penikmat kopi serius sebagai biji kopi dengan cita rasa yang unik. Menu baru inilah yang akan dimajukan sebagai menu khas dari Morfee Coffee.

Strategi pemilihan harga jual yang diterapkan oleh Morfee Coffee sudah tepat dengan pasar yang dituju, namun pemberian diskon tetap menjadi salah satu taktik harga yang tepat untuk meningkatkan jumlah pembelian. Rafiah (2020), menyatakan penawaran yang paling disukai mahasiswa di Janji Jiwa adalah diskon. Maka strategi promosi berupa diskon saat pandemi ini merupakan salah satu strategi promosi yang tepat di masa pandemi. Selain itu Asman (2021) juga menyatakan bahwa program diskon dapat menjadi pemasaran digital yang efektif dalam meningkatkan awareness dan branding Morfee Coffee khususnya program diskon yang melibatkan mitra online delivery seperti GrabFood dan GoFood karena dalam platform 
tersebut di mana interaksi terbatas, program diskon menjadi paparan bagi konsumen terhadap berbagai brand baru seperti Morfee Coffee.

Strategi pemasaran digital menjadi kunci utama bagi Morfee Coffee tidak hanya menjawab permasalahan penurunan omzet yang diakibatkan oleh pandemi, tetapi juga menjadi strategi dalam mengambil potensi pasar dan meningkatkan brand awareness. Rafiah (2020) menemukan bahwa generasi muda sebagai pasar sasaran utama kedai kopi mendapatkan informasi terkini tentang produk food \& beverage melalui aplikasi pesan antar online. Oleh karena itu, tepat jika Morfee Coffee mengoptimalkan kerjasama dengan mitra pesan antar online. Beberapa cara mengoptimalkannya adalah dengan terlibat dalam program diskon besar yang dimiliki mitra seperti program “cicipjjktiovo40\%” yang dimiliki GrabFood yang di mana justru banyak pelanggan yang menemukan brand baru pada program diskon rutin seperti ini.

Cara berikutnya adalah dengan melakukan kolaborasi bersama dengan Key Opinion Leader (KOL) atau influencer lokal. Berbeda dengan influencer besar, influencer lokal memungkinkan diajak kerjasama lebih menyeluruh ke dalam seluruh program kampanye pemasaran Morfee Coffee kini dan di masa depan dengan harga yang terbilang terjangkau (Asman, 2021). Rafiah (2020) menyatakan bahwa ulasan para influencer menjadi salah satu stimulus yang mempengaruhi keputusan pembelian generasi muda pada suatu produk pada masa pandemi. Oleh karena itu, Morfee Coffee dapat memilih menggunakan influencer sebagai sumber pesan dalam mengomunikasikan produk minuman kopinya. Morfee Coffee dapat memilih menggunakan influencer lokal karena relatif lebih murah dari sisi biaya.

Morfee Coffee dapat membuat pesan yang kreatif berupa konten seperti foto dan caption yang diposting di Instagram. Konten foto dapat menampilkan produk dan proses pembuatan kopi sehingga konsumen dapat mengetahui bahwa proses pembuatan kopi dilakukan secara aman dan mengikuti protokol kesehatan. Terkait caption, hal yang harus diperhatikan oleh Morfee Coffee adalah pemilihan kata yang sederhana, mudah diingat, menarik dan sesuai dengan konteks yang ada. Morfee Coffee juga dapat memilih hastag yang sedang tren di masyarakat agar mudah ditelusuri jejak digitalnya oleh target khalayak. Hal lain yang perlu diperhatikan adalah membangun interaktif dengan pelanggannya. Fitur likes dan komentar yang disediakan dalam media sosial seperti Instagram dan Facebook dapat menjadi media interaksi dua arah antara konsumen dengan perusahaan. Likes dan comment yang dilakukan oleh konsumen dapat menjadi bukti nyata dari $e-W O M$. Fitur likes dan komentar mendorong konsumen untuk memberikan respon berupa rekomendasi positif pada sebuah produk, jasa dan merek. (Lee \& Youn, 2009 dalam Agustine \& Prasetyawati, 2020)

Meskipun Morfee Coffee lebih berfokus pada penjualan online, namun Morfee Coffee dapat membuat papan besar dengan tampilan visual yang menarik dengan tujuan memudahkan, tidak hanya membuatnya lebih mudah ditemukan, tapi juga dapat menjadi penanda serta identitas di media sosial.

Morfee Coffee memilih untuk efisiensi jumlah karyawan demi melakukan penghematan, namun hal ini justru berpengaruh kepada kemampuan para co-founders dalam menentukan strategi-strategi baru agar Morfee Coffee untuk berkembang lebih besar. Morfee Coffee disarankan untuk mempekerjakan 1 asisten barista yang bertugas dalam membuat minuman, membantu manajemen stock, serta pembukuan. 
Protokol Kesehatan yang dilakukan Morfee Coffee sudah cukup baik. Selain protokol kesehatan, Morfee Coffee juga dapat menjelaskan proses pembuatan kopi dan minuman itu sendiri sebagai bagian dari strategi pemasaran. Hal ini dilakukan untuk menimbulkan rasa percaya kepada konsumen/calon konsumen terhadap kualitas yang Morfee Coffee berikan.

Aktivitas Morfee Coffee banyak dilakukan pada media online (mitra online delivery dan media sosial) maka Morfee Coffee perlu mempertajam bukti fisik yang ada di kedua media online tersebut. Pada mitra online delivery, Morfee Coffee perlu terlibat dalam program diskon rutin yang dimiliki mitra. Pada media sosial, Morfee Coffee perlu meningkatkan promosi berbasis digital dengan memperbaiki konten dan menggunakan jasa KOL/influencer lokal (micro influencer).

\section{SIMPULAN}

Berdasarkan hasil analisis dan pembahasan maka dapat disimpulkan bahwa Kedai Morfee Coffee belum memiliki strategi pemasaran yang terencana dengan baik dalam menghadapi kondisi pandemi ini, namun demikian Morfee Coffee masih memiliki ruang untuk berkembang dan potensi pasar yang masih terbuka jika mengoptimalkan strategi pemasarannya, khususnya dalam pemasaran digital. Pada situasi pandemi Covid-19, pemasaran digital menjadi solusi yang tepat dalam mengembangkan usaha kedai kopi melalui pemilihan layanan online yang cukup familiar seperti GoFood maupun GrabFood, meningkatkan promosi di media sosial, mengembangkan kreatifitas konten digital dan menggunakan KOL/infuencer lokal (micro influencer). Morfee Coffee juga perlu melakukan inovasi di produk agar memberikan nilai proposisi yang unggul dimata konsumen.

Kedai Morfee Coffee belum memiliki positioning, oleh karena itu pada penelitian selanjutnya dapat mengkaji positioning kedai kopi yang menggambarkan pemetaan diantara kedai kopi yang menggunakan layanan digital. Positioning ini menarik untuk dikaji agar kedai kopi dapat terus berinovasi dan membangun diferensiasi yang menjadi keunggulan kompetitif di masa pandemi ini.

\section{DAFTAR PUSTAKA (HALAMAN TERPISAH, BOLD, 11) / REFERENCES}

Agustine, M., \& Prasetyawati, Y. R. (2020). Pengaruh kualitas informasi Instagram dan electronic word of mouth terhadap citra dapurfit. PRofesi Humas, 5(1), 82-97. https://doi.org/10.24198/prh.v5i1.23966

Gama, M. A. (2018). Strategi Komunikasi Pemasaran Kopi Tjangkir 13. Jurnal Ilmu Sosial dan Ilmu Politik, 7(2), 148-153.

Hamdani, T. (2020, Maret 17). Restoran hingga Kedai Kopi Terancam Gulung Tikar Imbas Corona. detikcom. https://finance.detik.com/berita-ekonomi-bisnis/d4943285/restoran-hingga-kedai-kopi-terancam-gulung-tikar-imbas-corona 
Hamidah, N.A. \& Haqi, M.S. (2019). Strategi Pemasaran dan Analisis SWOT sebagai Pengembangan Usaha Kedai: Studi Literatur dan Perancangan Bisnis Kedai Loss Caffe. MARGIN ECO: Jurnal Bisnis dan Perkembangan Bisnis, 3(2), 14- 29.

Hendrawan, A., Sucahyowati, H., Cahyandi, K., Indriyani, \& Rayendra, A. (2019). Pengaruh Marketing Digital Terhadap Kinerja Penjualan Produk UMKM Asti Gauri di Kecamatan Bantasari Cilacap. Jurnal Administrasi Dan Kesekretarisan, 4(1), 53-60.

International Coffee Organization. (2021). Coffee production by exporting countries (May 2021) [Data Sets]. International Coffee Organization. https://www.ico.org/prices/poproduction.pdf

International Coffee Organization. (2021). World coffee consumption (May 2021) [Data Sets]. https://www.ico.org/prices/new-consumption-table.pdf

Kotler, P. \& Keller, K. L. (2016). Marketing Management (16th ed.). Pearson Education Limited.

Keller, K. L. (2008). Strategic Brand Management: Building, Measuring, and Managing Brand Equity (3th ed.). Pearson Prentice Hall, Inc.

Nasihin, M.A., Subagyo, S.E.F., Erfariani, S. A., \& Farida, S.N. (2020). Strategi Bisnis Era New Normal Pada Kedai Kopi di Surabaya: Studi Kasus Pada Beby's Coffee Surabaya. Jurnal Ilmiah Ekonomi dan Bisnis, 13(2), 76-78.

Oktaviani, F. \& Rustandi, D. (2018). Implementasi Digital Marketing dalam Membangun Brand Awareness. PRofesi Humas, 3(1), 1-20. https://doi.org/10.24198/prh.v3i1.15878

Prasetyo, W. B. (2020, February 21). 2020 Kedai Kopi Diprediksi Tumbuh 15\%. beritasatu.com. https://www.beritasatu.com/ekonomi/601687/2020-kedai-kopidiprediksi-tumbuh-15

Rafiah, K.K. (2020). Review Strategi Pemasaran Efektif Untuk UMKM Kedai Kopi Dalam menghadapi Masa Pandemi. Jurnal Ekonomi dan Bisnis Terapan, 16(2), 30-38.

Rangkuti, F. (2014). Analisis SWOT: Teknik Membedah Kasus Bisnis. Gramedia Pustaka Utama.

Soedarsono, D. K., Mohammad, B., Adamu, A. A., \& Pradita, K. A. (2020). Managing Digital Marketing Communication of Coffee Shop Using Instagram. International Journal of Interactive Mobile Technologies, 14(5), 108-118. 